\section{OS IMPASSES DA DEMANDA}

Quem precisa de análise hoje? O discurso analítico: novos sintomas e novos laços sociais. Tânia Coelho dos Santos. Rio de J aneiro, Bertrand Brasil, 2001, 333 p.

Andréa M artello

Bolsista deApoio Técnico (Faperj) do Núcleo Séphora de Pesquisas. Mestre em Teoria Psicanalítica (UFRJ).

A pergunta-título do livro de Tânia CoeIho dos Santos - psicanalista, professora adjunta no Programa de Pós-graduação em Teoria Psicanalítica da UFRJ - , "Quem precisa de análise hoje?", é desdobrada em várias outras perguntas, tanto complexas e pertinentes quanto incômodas, em relação à psicanálise, sua teoria, sua clínica e seu processo de difusão.

Poderíamos, para começar, partir de uma pergunta que o livro nos indica e que freqüentemente acossa a psicanálise: pode ela operar para além de um dispositivo de normatividade, atualizando indivíduos traumatizados pelo impacto da modernidade? A modernidade como condição de possibilidade para 0 advento da psicanálise tem o poder de restringi-la a uma mera ferramenta terapêutica?

Explicitando melhor o tema do livro, podemos dizer que ele discorre sobre a responsabilidade da psicanálise nessa res- trição que lhe é imposta, em forma de demanda, pelos tempos modernos. Deste modo, ele trata não só do tipo de demanda que a psicanálise construiu em seu processo de difusão mas também do modo como respondeu ou não a esta demanda.

A autora parte de uma pesquisa sobre a difusão da psicanálise no Brasil por meio das revistas femininas a partir da década de 1960 colocando de outra forma nossa questão: pode a psicanálise transpor, no seio de seu processo de difusão pelos meios de comunicação de massa, as barreiras da transferência que produz? Ou ainda, deve a psicanálise responder à demanda de felicidade, racionalidade e autonomia produzida pelo seu processo de difusão uma vez que a ele está atrelada a modernização científica do laço social?

Vejamos.

0 aconselhamento pré-psicanalítico veiculado pelas revistas femininas nos anos 1950 serve à defesa dos interesses de uma sociedade que se pretende anterior e maior que todo indivíduo, mas cujos efeitos não são percebidos como uma determinação inconsciente. Encontramos um ideal de complementaridade entre os sexos calcado na discriminação dos papéis de homem e mulher, numa sociedade que partilha, em sua maior parte, dos mesmos códigos de valores, e estes, por sua vez, são estabelecidos a partir de uma hierarquia evidente e mais ou menos incontestável. 
Na década de 1960 há uma ruptura com esse universo tradicional criticando a intenção repressiva que se oculta pela valorização do ideal ligado ao gênero. Os meios de comunicação passam a difundir uma psicologia cujo modelo de eu é forjado com categorias do pensamento psicanalítico. Neste processo, o conceito psicanalítico de maior vigor é o de recalque e complexo de Édipo em sua perspectiva repressiva e, portanto, evitável pelo discurso racional e corajoso, na medida que força a mudança de valores e mentalidades.

Neste momento, a difusão da psicanálise leva os leitores leigos das revistas femininas a acreditarem que a prática psicanalítica se baseia no diálogo, na razão científica e na explicação interpretativa. O epicentro dessa prática é a elucidação da constituição dos sujeitos e das relações sociais a partir de estruturas universais, como, por exemplo, o complexo de Édipo. A estratégia da difusão consiste em ensinar que todo indivíduo é responsável pelas razões inconscientes que determinam suas condutas e escolhas.

Os anos 1970 foram profundamente marcados pelo movimento feminista da igualdade entre os sexos. Nesse período, observamos um verdadeiro combate contra a infelicidade no casamento. Ser feliz torna-se obrigatoriedade moral, higiênica e científica, a partir de uma ordem social moderna, igualitária e livre guiada pelo ideal de autenticidade. 0 psicologismo ganha força pois promete garantir a transparência do eu para si e para o outro. A difusão da psicanálise estabelece por conseguinte um tipo específico de demanda de análise: a demanda do autoconhecimento.

No curso de duas décadas haverá uma imensa disseminação do saber teórico da psicanálise, a serviço de uma ideologia analítica que trabalha em prol da modernização dos costumes. $E$, sem dúvida, "a modernização social foi um sucesso" (p. 150), no entanto, como diz a autora: "o projeto igualitário foi decepcionante. Fracassou, justamente, em conseqüência do seu sucesso" (idem).

Nos anos 1980, os temas abordados pelo discurso analítico dirão respeito aos custos, para ambos os sexos, das conquistas femininas dos anos 1970: a solidão, a angústia, a indecisão e a autodesvalorização. Num processo de resposta à demanda que criou, e portanto criando mais demanda ainda, a psicanálise do período tem no conceito de narcisismo um operador ambíguo que serve tanto para denominar determinadas posições patológicas quanto, saindo do ideal de igualdade entre os sexos da década anterior, cultivar um novo ideal, o de "seja você mesmo". "Tempos sombrios", este é o título do terceiro capítulo que trata do equívoco desta cultura psicanalítica do narcisismo.

Temos então uma radiografia que mostra a difusão da psicanálise como a difusão de um campo de saber que veicula uma ideologia modernizadora de inspiração racionalista e que cultiva dois ideais caros ao individualismo: a igualdade entre os sexos e as gerações, e a individualidade única de cada um.

Como conseqüência lógica da ideologia que colocou a relação intersubjetiva como valor central - calcada no diálogo como via de autoconhecimento, na independência e na autodeterminação dos indivíduos - , temos um novo individualismo que "tende a radicalizar-se, a transcender as fronteiras de uma individualidade limitada pelo diálogo e a caminhar para a reivindicação de um direito absoluto à própria individualidade" (p. 100). 
É dessa forma que a autora trata da intrincada conexão entre individualismo e psicanálise, na qual, por um lado, a ideologia individualista e científica da modernidade se serve da racionalidade analítica para se propagar, e, por outro, essa mesma ideologia presta-se aos objetivos da difusão da psicanálise, pois alimenta a demanda de análise.

Concomitantemente a esta posição delicada e duvidosa que 0 ritmo de difusão da psicanálise a conduz nos anos 1980, teremos a emergência da influência da teoria lacaniana no Brasil, inaugurada com a crítica de Lacan, nos anos 1950 e 60, à posição psiquiatrizante, psicologizante e pedagogizante da psicanálise pósfreudiana.

Todo o percurso anterior de difusão da psicanálise foi duramente criticado pelo pressuposto lacaniano de que 0 'inconsciente é estruturado como uma linguagem'. Lacan promove a idéia de que 0 'eu é um outro' e que o inconsciente, para além do que é interpretável, mantém sua incidência imperativa. Não há autoconhecimento suficiente para o sujeito do inconsciente e, muito menos, autonomia ou independência em relação ao outro. Muito pelo contrário, a crença nesses ideais e 0 insucesso efetivo que eles geram produz a angústia e o desejo por mais liberdade, mais autonomia e mais independência. 0 correlato da difusão da psicanálise a serviço da modernização social e da dominância do discurso científico não foi a felicidade no amor e no sexo livre e sim o aprofundamento da insatisfação.

Vemos assim se delinear o panorama dos sintomas contemporâneos que submetem 0 sujeito a imperativos pulsionais de uma sociedade marcada pelo discurso científico, pelo individualismo e pelo capitalismo. E poderíamos também dizer: marcada por uma difusão da psicanálise que traz a marca de seu uso por esses discursos da era moderna.

No entanto, terá sido mesmo um erro, um engano, um engodo, o processo de difusão da psicanálise? Seria possível haver difusão e constituição de demanda analítica sem passar por uma ideologização do saber analítico? Talvez não. Talvez tenhamos que tratar essa questão como uma das mais pertinentes da psicanálise e é disso que trata a parte IV do livro: o desejo do analista para além da ciência e da religião.

Como nos sugere a autora, a psicanálise, para se difundir no campo da informação, se oferece por meio do discurso da ciência. Em conformidade com a ciência, a psicanálise supõe e especifica uma técnica de abordagem da verdade, a verdade do inconsciente, que implica o sujeito e se encontra para além dos limites de um subjetivismo autoconsciente de opiniões e crenças. Esse é o ponto em que a psicanálise tangencia a abordagem científica e no qual pode se confundir com ela a partir de uma teoria construída sobre universais psíquicos.

Se há essa aproximação, coube, no entanto, à psicanálise reintroduzir na modernidade o que fora excluído da ciência, o sujeito, que retorna numa dimensão inconsciente como sonho, fantasia e sintoma que trazem à luz o desejo inconsciente. É nesse ponto que a verdade para a psicanálise se estabelece como realidade psíquica. Inescapável, não há abordagem do real que não seja pela via da realidade psíquica com todo o caldo desejante que Ihe define, desde Freud, uma vez que o propósito de qualquer abordagem da realidade é reencontrar a experiência de satisfação.

É por esse mesmo motivo que a psicanálise não pode desconsiderar que 0 
efeito primário de adesão ao seu campo, como qualquer outro campo, éo da crença religiosa, mesmo que seja crença no poder do inconsciente:

\section{“Freud sempre manteve dentro do campo conceitual psicanalítico uma preferência pela ciência em detrimento da religião. Isso não impediu que ele estivesse perfeitamente advertido quanto ao que uma prática analí- tica possa ter que manejar de religião, ilu- são e crença. A essa dimensão chamou trans- ferência." (p. 157)}

Para Lacan, trata-se, na transferência e na demanda, de transpor o umbral da crença no 'Outro que sabe' para a descoberta de que esse saber é lacunar e é como ficção que o sujeito aborda a verdade de sua afetação por esse Outro anterior.

Deste modo, a autora estende, com sucesso, o conceitual teórico da psicanálise a ela própria no que tange ao seu processo de difusão.

Ciência, religião e individualismo. Complexas são as aproximações e distanciamentos com o corte da modernidade que a psicanálise ou está submetida ou deve efetuar desde sua fundação, passando pela difusão e a presença de suas intervenções na cultura. Podemos dizer que o livro lança uma indagação a respeito do grau de lucidez dos psicanalistas nesse processo.

Para a autora, raramente a ideologização é percebida como dimensão essencial da difusão da psicanálise, e raramente a intervenção analítica é encarada como ação política. A riqueza desta questão se manifesta na medida em que não basta reavaliarmos o passado com olhos críticos - e, vale dizer, com os olhos da crítica de Lacan - se não ponderarmos essa dimensão política da intervenção analítica. A psicanálise não está suspensa acima dos saberes de sua época. Há história, há um contexto social, códigos morais e preocupações éticas que especificaram seus atos interpretativos, em alguma medida eficazes.

Considerar a ideologia pelo viés marxista definindo-a como ilusão ou engodo é, segundo a autora, ignorar que a descoberta do inconsciente é a promoção da verdade como estrutura de ficção. Isto "alimenta a resistência dos analistas a integrarem a dimensão política da cultura psicanalítica ao campo teórico" (p. 176), é desconhecer uma teoria do poder inerente ao pensamento analítico.

A tese de que há uma teoria do poder inerente ao conceito de pulsão é explicitada a partir de uma analogia com a teoria do poder em Foucault. Em ambos os casos, pulsão e poder, trata-se de considerar a positividade dos efeitos dos discursos, que de forma inarredável produzem mudanças. Para Foucault, o poder se exerce principalmente em sua esfera descentralizada e para Freud tem um estatuto inconsciente. Essa analogia toma uma parte considerável do livro, analisando suas aproximações e as críticas de Foucault à psicanálise bem como o modo como podemos re-situá-las a partir de uma definição de poder como aquilo que não se deixa dominar.

Para toda a argumentação exposta sobre o corte da modernidade, localizando os mais diferentes autores como Foucault, Marx e Althusser, Dumont, Donzelot, Ariés, Ussel, entre outros, temos, em suas palavras, que:

\footnotetext{
“a lógica da exposição que se segue não é filosófica, sociológica ou antropológica como poderia parecer. É rigorosamente psicanalítica. (...) a possibilidade de uma metapsicologia do social não se reduz a uma psicossociologia, pois se sustenta no
} 
reconhecimento da natureza inconsciente do laço social". (p. 200-201)

É disso que o livro trata em seus próximos capítulos, explicitando o pensamento sobre a modernidade, o declínio de Deus, o reforço e o declínio da função paterna, a mudança da estrutura familiar e dos laços sociais, até a abordagem da condição contemporânea, com suas novas formas de mal-estar, de laços, de gozo e de sintomas.

A modernidade inaugura 0 sujeito jurídico quando, perante a lei, todo homem é livre, igual e racional. Este corte da modernidade instaura concomitantemente, pelo avesso, o sujeito do inconsciente. Um excedente não previsto pela lógica jurídica, já que se produz, justamente, por sua exclusão. Para além de um déficit, há, na verdade, uma "ultrapassagem" da esfera centralizada de representação jurídica. Autores como Freud, Foucault e Lacan precisam ser compreendidos dentro dessa lógica.

Foucault analisa as "relações concretas de poder" a partir de uma concepção de "estratégias sem sujeito" - que, a despeito de funcionarem como um conjunto mal ordenado de confrontos localizados, são capazes de assumir uma coerência - divergindo das teorias do contrato social, e ultrapassando aquilo que define o jurídico, ou seja, a oposição indivíduo $x$ sociedade. Essa ultrapassagem da concepção jurídica de poder 0 aproxima da obra freudiana.

Assim como para Freud a sexualidade não se reduz à genitalidade, para Foucault o sexo não se reduz ao dispositivo de aliança. À aliança se acrescenta o dispositivo da sexualidade. Percorrendo sua História da sexualidade, e até confrontando Foucault com Foucault, a autora questiona sua denúncia de que a psicanálise, ao colocar o sexo em discurso, faria parte de uma estratégia para submeter todo o poder a um novo imperativo, o 'sexo Rei':

"Devemos admitir que essa crítica se sus-
tenta de acordo com o que foi difundido
da teoria de Freud sobre a repressão da
sexualidade pela civilização, no entanto, na
contemporaneidade vemos que se por um
lado os indivíduos ganharam mais liberda-
de para inventar novas maneiras de gozar e
viver, em contrapartida mais do que nunca
está instaurado o mal-entendido nas rela-
ções amorosas." (p. 252)

Trata-se de resgatar o que há de subversivo na pulsão e não reduzi-la ao dispositivo da sexualidade, uma vez que esse último teria servido apenas para modernizar o dispositivo da aliança. Nesse ponto é Foucault que ainda serve como guia, já que sua arqueologia da psicanálise se integra a uma arqueologia do sujeito do prazer e se estende até a Grécia antiga. A problematização moral sobre o comportamento sexual não pode ser creditada exclusivamente às ideologias individualistas dos séculos XVIII e XIX. Na mesma direção, no capítulo VII, a autora estabelece uma equivalência entre a noção de dispositivo em Foucault e a noção de discurso em Lacan. Deste modo, provoca um confronto entre a teoria de Foucault, precisamente sobre 0 dispositivo da sexualidade, com a teoria dos quatro discursos de Lacan e, mais especificamente, com o discurso analítico. Ela argumenta que, neste último, para além daquilo que se possa saber sobre o sexo ou sobre si, 0 analista é efetivamente aquele que evoca o fracasso deste saber: "a experiência analítica mostrou que só há evocação da verdade como meio-dizer. Para além de sua metade não há nada a dizer" (p. 246). 
Diante da repetição pulsional, nenhum dispositivo de poder tem a garantia de que será bem sucedido. 0 poder, em última instância, tem relação com o ser e triunfa sobre todas as produções de saber e do prazer. Todo poder sobre o sexo, todo desejo de liberação sexual, toda colocação do sexo em discurso está fadado, pelo seu fracasso, a recomeçar novamente.

É nesse ponto que o pensamento sobre uma segunda clínica de Lacan tem pertinência. Uma clínica que se desloca do axioma de "o inconsciente estruturado como uma linguagem" para aquele em que "a relação sexual não existe". Que mudanças se operam a partir daí? Como pode a psicanálise operar o seu discurso libertário ou, ao contrário, seu discurso de responsabilidade simbólica, se hoje tratamos com a inconsistência do grande $\mathrm{Ou}$ tro que ela própria ajudou a desvendar?

A questão pode se apresentar de outra forma: seria possível conduzir os indivíduos modernos submetidos ao ideal de ciência que os lança à deriva no campo do saber, rumo ao ideal de análise? Ou ainda, a psicanálise pode constituir uma clínica que leve a cabo a potência última de sua descoberta, ou seja, o poder do fracasso de todas as produções de saber e dispositivos de prazer que se arrojam na tentativa de garantir o gozo?

Para terminar, o que podemos dizer é que o livro não somente lança essas e outras tantas questões como também assume o risco, político, de tentar respondê-las.

Recebido em 21/ 8/ 2002.

Aprovado em 9/9/2002.

André Martello

Rua Eduardo Santos 161/ 201

20251-460 SantaTereza

Rio de Janeiro RJ

Tel.: 2507-5464 / 9197-5567

martello@uninet.com.br

\section{POR UMA PSICANÁLISE POIÉTICA}

\section{$A$ invenção da vida: arte e}

psicanálise. A. Slavutzky, E. L. A. de

Sousa, E. Tessler (orgs.), Porto Alegre,

Artes e Ofícios, 2001, 191 p.

\section{André M artins}

Psicanalista. Doutor em Filosofia pela Université de Nice, França; doutor em teoria psicanalítica pela UFRJ; professor adjunto dos cursos de Pós-graduação em Medicina, Saúde Coletiva e Filosofia da UFRJ.

"Arte e psicanálise", diz o subtítulo de A invenção da vida. No entanto, muito mais do que correlacionar arte e psicanálise, este livro organizado por dois psicanalistas e uma artista plástica gaúchos, reunindo artigos de psicanalistas e artistas de Porto Alegre, São Paulo e Paris, se propõe a pensar a própria psicanálise como atividade criativa - como elemento capaz de contribuir ativamente para uma modificação criativa nos afetos e na dinâmica de vida do paciente. Ou mesmo de constituir-se tal como uma arte, não só em seu domínio clínico mas também teórico e cultural.

Stéphane Huchet delimita esta diferença: "houve um tempo, no país de Lacan (là, quand...), em que a psicanálise representou um espectro ideológico incontornável na paisagem crítica da arte e da literatura. Ideológico, isto é, de captura e de fechamento a priori da realidade por tal modelo teórico." Exercício dogmático de submissão da arte à suposta Verdade epistemológica da psicanálise, constituindo assim "um freudismo fundamentalista", segundo o qual "a teoria psicanalítica (...) era concebida como o único modelo teórico capaz de dar conta da realidade, que não poderia ter sentido senão por meio da grade sobretudo freudiana", relata Huchet. A arte moder- 